\title{
Processo de validação e adaptação transcultural do assessment of interprofessional team collaboration SCALE II (AITCS II)
}

\author{
Emanuella Pinheiro de Farias Bispo, Rosana Aparecida Salvador
}

\begin{abstract}
Resumo
Introdução: A construção e validação transcultural de instrumentos é um processo complexo. Nos últimos 30 anos de estudos, diversos instrumentos internacionais foram elaboradas, desenvolvidos e testados com objetivo de avaliar a colaboração interprofissional. Dentre os instrumentos destaca-se o Assessment of Interprofessional Team Collaboration Scale II - AITCS II (ORCHARD, 2015), devido a sua pertinência e a possibilidade de avaliar a competência dos profissionais de saúde quanto à colaboração interprofissional. O AITCS II é um instrumento diagnóstico desenvolvido para medir a colaboração interprofissional entre os membros de uma equipe. Consiste de 23 assertivas com características da colaboração interprofissional (como uma equipe trabalha e atua). Os itens da escala representam três dimensões consideradas fundamentais para a prática colaborativa: 1) Parceria -8 itens; 2) Cooperação -8 itens; e, 3) Coordenação -7 itens. Neste contexto, a validação do AITCS II representa um avanço diante da escassez de instrumentos de avaliação da Educação Interprofissional (EIP), aprendizagens compartilhadas e práticas colaborativas disponíveis no Brasil. Dessa forma, os temas centrais desenvolvidos no presente estudo versam sobre a EIP e a prática colaborativa em saúde. Vale ressaltar que na EIP as profissões aprendem conjuntamente sobre o trabalho coletivo e as especificidades de cada área profissional, orientadas para o trabalho colaborativo em equipe interprofissional (OMS, 2010). Para Ellery (2014), a prática colaborativa diz respeito ao trabalho em equipe realizado nos serviços de saúde. Os resultados da aprendizagem na perspectiva da EIP e da prática colaborativa é ter um profissional de saúde colaborativo e preparado para a prática interprofissional (WILLGERODT, 2015; OMS, 2010). Contudo, para que se haja informações sobre o nível de colaboração dentro de ambientes de saúde, requer-se mecanismos para avaliar esta prática. Desse modo, com a notória escassez de estudos brasileiros na investigação de processos relacionados à avaliação da interprofissionalidade, este texto apresenta um recorte da construção de uma tese de doutorado em andamento, a qual possui como uma das etapas a tradução e a adaptação transcultural do Assessment of Interprofessional Team Collaboration Scale II - AITCS II (ORCHARD, 2015). Objetivo: O estudo teve como objetivo realizar a tradução e a adaptação transcultural da versão do Assessment of Interprofessional Team Collaboration Scale II - AITCS II (ORCHARD, 2015) para o português brasileiro. Método: O presente estudo, de caráter metodológico, foi realizado no período de Agosto de 2016 a Outubro de 2017 e percorreu as seguintes etapas: no Processo de Tradução e Validação: Avaliação de equivalências conceitual e de itens; Avaliação da equivalência semântica; Equivalência Operacional; Equivalência de Mensuração. A tradução do inglês para o português e a adaptação transcultural da versão do AITCS II está fundamentada e baseada na descrição original do Assessment of Interprofessional Team Collaboration Scale II (ORCHARD, 2015). Para este processo obteve-se a autorização oficial da autora canadense do AITCS-II, Dr ${ }^{\mathrm{a}}$ Carole Orchard. Resultados: Procedimentos de Validação - A seguir descreve-se o procedimento utilizado para a tradução e validação transcultural do instrumento. Na Etapa 1 "Avaliação de equivalências conceitual e de itens", foi examinado se havia relevância e correspondência dos conceitos, de modo semelhante, nas duas culturas, originária e alvo. Para essa etapa, foi utilizada revisão bibliográfica e discussões com especialistas da área. No que diz respeito a equivalência conceitual foi realizado estudos e reflexões sobre a teoria que envolve o construto "prática colaborativa interprofissional" e
\end{abstract}


ISSN 2179-6750

o domínio alcançado pela utilização do instrumento. Para tanto, foi revisado o modelo conceitual que dá sustentação teórica ao construto, com base em uma revisão da literatura nacional e internacional sobre a temática. A Etapa 2 "Avaliação da equivalência semântica" avaliou a transferência de significados entre línguas. Fez parte do processo a atenção às especificidades de significado referencial e conotativo. Esta etapa foi subdivida em quatro fases: 1. Tradução do instrumento original: Nesta fase, dois tradutores foram convidados para realizar as traduções do instrumento original do inglês para o português. Estes tradutores tiveram conhecimento do objetivo da pesquisa e realizaram traduções do original em inglês para o português, de modo independente, gerando duas traduções. 2. Retraduções. Nesta fase de retradução, outros dois tradutores realizam a tradução de volta ao idioma original (back-translation) do português para o inglês. 3. Revisão pelo Comitê de Juízes. Para esta fase do processo de "Equivalência Semântica" foi organizado um Comitê de Juízes. O Comitê de Juízes consolidou todas as versões produzidas em uma única versão, em português, por meio da avaliação dos itens quanto às equivalências semântica, idiomática, cultural e conceitual. 4. Pré-teste. Esta etapa correspondeu a aplicação, da versão adaptada, em um grupo de 20 a 30 profissionais que apresentavam características da população-alvo. Para este momento, o instrumento foi aplicado em pré-teste com 20 docentes do curso de fonoaudiologia de uma universidade pública. O pré-teste teve por finalidade assegurar se a versão, após, a revisão pelo Comitê de Juízes, preservou equivalência à versão original, além de detectar possíveis equívocos, pois avaliou não somente a qualidade da tradução, como também os aspectos práticos de sua aplicação. A Etapa 3 "Equivalência Operacional" consistiu em manter as características operacionais do procedimento original, propiciando maior confiabilidade e validade do instrumento. Esta fase foi confirmada, também, com o pré-teste realizado na Etapa 2 (Avaliação da equivalência semântica). Algumas modificações foram realizadas, o que tornou o instrumento mais compreensível e mais familiar ao cenário cultural brasileiro. A Etapa 4 "Equivalência de Mensuração" consistiu em avaliar as medidas de confiabilidade e a validade da versão final do instrumento. Para esta etapa, foi conduzido um estudo-piloto com uma amostra de 15 docentes de diversas áreas de conhecimento na Saúde e teve como objetivo verificar os detalhes sobre a aplicabilidade do instrumento como a clareza e tempo de aplicação. Após 15 dias da primeira aplicação, o teste foi reaplicado com a mesma amostra de docentes. Considerações: O instrumento foi submetido à análise estatística após passar por todas as etapas do processo de tradução e validação transcultural, inclusive, após ter sido submetido a fase final de Equivalência de Mensuração. O AITCS II está sendo preparado para ser aplicado com docentes dos cursos de Terapia Ocupacional das Instituições de Ensino Superior (IES) do Nordeste do Brasil, para atender ao objetivo de Avaliar a formação do docente para o ensino e a prática colaborativa interprofissional dos cursos de Terapia Ocupacional do Nordeste do Brasil como parte da tese em andamento, intitulada "O olhar dos docentes de Terapia Ocupacional do Nordeste: formação e prática interprofissional”. A etapa de tradução e adaptação transcultural está em andamento e espera-se que os índices estatísticos de consistência e concordância sejam viáveis para dar prosseguimento à fase de Equivalência Operacional.

Descritores: Estudos de validação, Relações interprofissionais, Escalas, Equipe de assistência ao pacientes, Formação. 